\title{
Novel targets and strategies to combat borreliosis
}

\author{
Martin Strnad $^{1,2}$ (I) $\cdot$ Libor Grubhoffer ${ }^{1,2} \cdot$ Ryan O.M. Rego ${ }^{1}$
}

Received: 18 November 2019 / Revised: 5 January 2020 / Accepted: 12 January 2020 / Published online: 17 January 2020

(C) Springer-Verlag GmbH Germany, part of Springer Nature 2020

\begin{abstract}
Lyme borreliosis is a bacterial infection that can be spread to humans by infected ticks and may severely affect many organs and tissues. Nearly four decades have elapsed since the discovery of the disease agent called Borrelia burgdorferi. Although there is a plethora of knowledge on the infectious agent and thousands of scientific publications, an effective way on how to combat and prevent Lyme borreliosis has not been found yet. There is no vaccine for humans available, and only one active vaccine program in clinical development is currently running. A spirited search for possible disease interventions is of high public interest as surveillance data indicates that the number of cases of Lyme borreliosis is steadily increasing in Europe and North America. This review provides a condensed digest of the history of vaccine development up to new promising vaccine candidates and strategies that are targeted against Lyme borreliosis, including elements of the tick vector, the reservoir hosts, and the Borrelia pathogen itself.
\end{abstract}

Keywords Lyme borreliosis $\cdot$ Vaccine candidates $\cdot$ Anti-tick strategies $\cdot$ Human pathogen $\cdot$ Public health

\section{Introduction}

Lyme borreliosis, or Lyme disease, is the most common ticktransmitted disease worldwide and is known to infect humans as well as domestic animals including cattle, cats, and dogs (Krupka and Straubinger 2010). Since the discovery of Lyme borreliosis in 1975 (Steere et al. 1977), a great deal of effort has been dedicated to the goal of preventing the detrimental effects of this disease. Despite improvements in diagnostic tests and public awareness of Lyme borreliosis, up to 300,000 cases in the USA (Kuehn 2013) and 65,000 cases in Europe (Hubálek 2009) are reported. However, the number of infections in Europe is likely to be an underestimation, as not all countries have made Lyme borreliosis a mandatorily notifiable disease (Smith and Takkinen 2006). The agents responsible for Lyme borreliosis are a diverse group of spirochetal bacteria within the Borrelia genus. Borrelia burgdorferi

Martin Strnad

martin.strnad.cze@gmail.com

1 Biology Centre, Institute of Parasitology, Czech Academy of Sciences, Branisovska 31, 37005, Ceske

Budejovice, Czech Republic

2 Faculty of Science, University of South Bohemia, Branisovska 31, 37005, Ceske Budejovice, Czech Republic sensu lato complex comprises at least 20 named species (Margos et al. 2019), with most human Lyme cases being caused by B. burgdorferi sensu stricto, B. afzelii, B. garinii, and B. bavariensis (Stanek et al. 2012).

B. burgdorferi is an extracellular pathogen (Strnad et al. 2015) that can infect the skin, heart, and nervous system (Cadavid et al. 2000; Stanek and Strle 2018). Ticks of the genus Ixodes transmit B. burgdorferi between reservoir hosts such as small mammals, lizards, and birds and are the only natural agents through which humans have been shown to be infected (Steere 2001). The principal vectors are Ixodes ricinus in Europe, Ixodes persulcatus in Asia, and Ixodes scapularis in North America. The overall prevalence of infected ticks and Borrelia genospecies distribution are highly variable across geographic locations (Strnad et al. 2017).

Ticks most often acquire Borrelia from infected rodents during their larval feeding. After molting to the next developmental stage, the tick has to find a new host. Upon ingestion of new blood, the spirochetes migrate from the midgut to the salivary glands of an infected tick followed by entering the mammal through the bite site (Ribeiro et al. 1987). The pathogen then disseminates throughout the mammalian host to establish an infection (Moriarty et al. 2008; Norman et al. 2008). All these concerted movements in the two environments are assumed or known to involve the process of motility and adhesion to cells involving a high number of protein and carbohydrate-based interactions (Ebady et al. 2016; Vechtova 
et al. 2018). Infected nymphal ticks occasionally feed on humans and most likely transmit the spirochete and cause human Lyme borreliosis as they are abundant in the spring and early summer and are small and difficult to detect. Unlike B. miyamotoi, B. burgdorferi sensu lato is considered not to be transmitted transovarially from female ticks to their offspring. However, several recent studies have shown that field-collected I. ricinus larvae may contain borrelial DNA (Kalmár et al. 2013; Tappe et al. 2014) and are able to transmit B. afzelii to laboratory rodents (van Duijvendijk et al. 2016), suggesting the potential role of larvae in spreading the Lyme borreliosis agent.

In the absence of antibiotic therapy, disseminated B. burgdorferi can persist in an individual for months or years even in the face of strong immune response. Currently, antibiotic treatment is the only effective tool to clear the infection and fight against Lyme borreliosis as no vaccine for humans is available. There are a number of new promising vaccine candidates being currently developed and tested by the research community, representing new hopes for future victims of the disease. These direct anti-Borrelia strategies can be complemented with anti-tick vaccines to bring a whole new level of human protection (Fig. 1), as will be discussed in this review.

\section{On-demand treatment strategies}

Most cases of Lyme borreliosis can be easily managed if treated early using antibiotics. Post-infection treatment is usually managed with antimicrobial agents for 2 to 4 weeks. Doxycycline, amoxicillin, penicillin $\mathrm{V}$, and cefuroxime are highly effective and are the preferred antibiotics for the treatment of early localized infection (Stanek and Strle 2018). Early disseminated infection is usually treated with intravenous ceftriaxone or penicillin (Stanek and Strle 2018) or oral doxycycline (Ljøstad et al. 2008). The most common routes of antibiotic administration are oral administration and intravenous injection. As an alternative approach, the topical application of $4 \%$ azithromycin cream was tested (Piesman et al. 2014). The result of the study showed that azithromycin was highly efficient when applied topically at the sites of tick bites in mice (Piesman et al. 2014). The outcomes of the study were however not fully confirmed in human studies (Schwameis et al. 2017; Shapiro and Wormser 2017). Azithromycin is an attractive possibility because of its good safety profile, long half-life in tissues, and potency against various $B$. burgdorferi species (Lee and Wormser 2008). Topical application of antimicrobial agents is a very attractive delivery method for a number of reasons and could be potentially used to stop the progression of the disease in the early localized stage of infection. The advantages include smaller amount of drug to be used, avoidance of the metabolic processing of the drug in the liver, ease of administration especially for young children, higher concentration of the drug to the affected area, and fairly diminished effects on nontargeted body locations such as intestinal florae. The transdermal route apart from the abovementioned advantages may be more convenient also for patients who cannot use normal oral intake because of swallowing problems such as intubation, deep sedation, or concurrent diseases (Tanner and Marks 2008). However, as a very motile organism, $B$. burgdorferi spread readily and very fast all over the body from site of skin entrance. Therefore, the
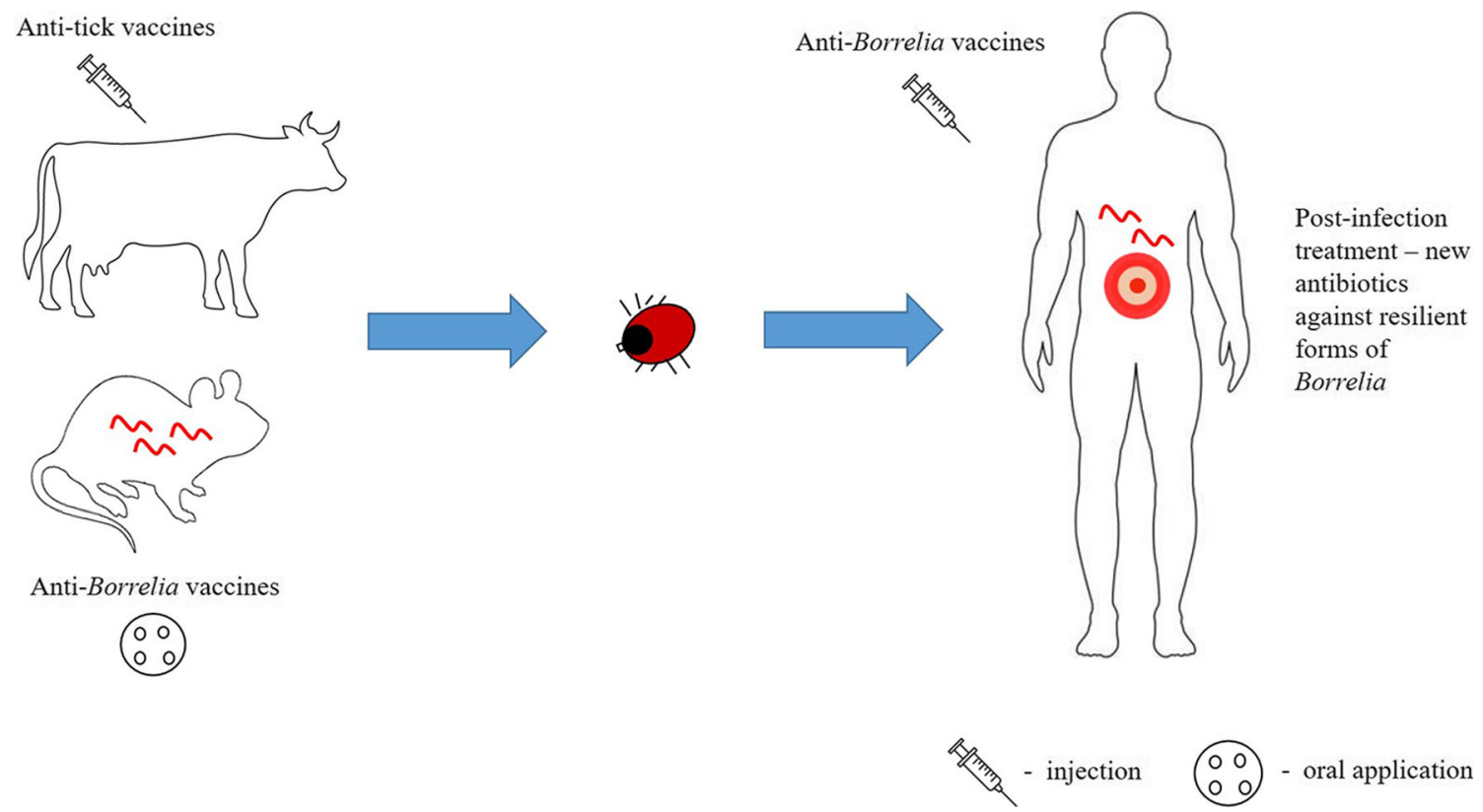

Fig. 1 The intensive research areas of current anti-Borrelia strategies. The focus is set on direct prophylactic anti-Borrelia strategies as well as on antitick vaccines 
risk of Lyme borreliosis is substantially increased when tick bites are unrecognized, and the topical treatment of tick bite site is not managed soon enough after onset of tick feeding.

Antibiotic prophylactic treatment, or chemoprophylaxis, can be loosely defined as the administration of drug/antibiotics to prevent the development of a disease at the very beginning before the symptoms arise. This treatment strategy can also potentially play an important role as a method to prevent $B$. burgdorferi dissemination (Lascher and Goldmann 2016). Chemoprophylaxis with a single high dose of doxycycline after removal of tick from the patients within $72 \mathrm{~h}$ was found beneficial in the USA. During a 6-week follow-up period, 1 of 235 treated patients developed erythema migrans, whereas 8 of 247 in the placebo group developed this skin condition, showing that antibiotic prophylaxis may significantly reduce the chances of developing Lyme borreliosis (Nadelman et al. 2001; Warshafsky et al. 2010). However, the unnecessary (over)use of antibiotics may lead to accelerated antibiotic resistance and is not generally recommended.

\section{New antibiotics against Lyme borreliosis}

While still a matter of dispute (Auwaerter and Melia 2012; Baker and Wormser 2017; Wormser et al. 2017), there are several reports of antibiotic treatment unable to fully eradicate B. burgdorferi from blood and tissues (Rudenko et al. 2016). The phenomenon of tolerance to otherwise lethal doses of antibiotics and the antibiotic resistance is often attributed to so-called B. burgdorferi persisters. At least three morphological forms of persistent $B$. burgdorferi were described based on observations from experimental studies. They are capable of forming round bodies, L-forms, and biofilm-like structures. Persisters may remain viable despite antibiotic therapy and are able to reversibly convert into motile spirochetal forms under favorable conditions (Timmaraju et al. 2015; Vancová et al. 2017; Rudenko et al. 2019). The mechanism that makes the bacterium less susceptible to killing by therapeutic doses of antimicrobials is not known; however, human neutrophil calprotectin was shown to make $B$. burgdorferi more tolerant to penicillin (Montgomery et al. 2006). B. burgdorferi in culture can also become tolerant to antibiotics used in treating Lyme borreliosis such as ceftriaxone, doxycycline, and amoxicillin (Feng et al. 2014; Sharma et al. 2015).

If the still limited but slowly growing number of evidence supporting the existence of chronic/persistent Lyme borreliosis will end up being accepted by the Lyme community, new antibiotics or targeted designer drugs to treat the Lyme spirochetes will be needed to cope more efficiently with the outcomes of the disease (Stricker and Middelveen 2018). Some studies suggest that treatment of a borrelial infection with the currently available antimicrobial agents may suppress but not eradicate the infection (Middelveen et al. 2018). Therefore, new drug candidates have been investigated and found using high-throughput screening of existing FDA-approved drugs in the USA (Feng et al. 2014; Feng et al. 2015; Pothineni et al. 2016), with the ultimate goal of complete microbial eradication and clinical cure. The usefulness and potential application in human medicine will have to be evaluated.

\section{Prophylactic treatment strategies}

\section{Anti-Borrelia strategies: human-targeted approaches}

Research efforts have long focused on ameliorating the symptoms and consequences of disease through treatment, commonly using various kinds of broad-spectrum antibiotics. However, prevention of the disease is far preferable to treating the short- and long-term often debilitating consequences of the disease. Human vaccination has greatly reduced the burden of infectious diseases and prevented more suffering than any other form of medical activity (Andre et al. 2008). Prophylactic vaccination of humans was the first choice for companies and health organizations for prevention of Lyme borreliosis. Despite a plethora of highly antigenic and immunologically accessible borrelial surface-exposed proteins (Gilmore et al. 1996; Hanson et al. 1998; Probert and Johnson 1998; Fikrig et al. 2004), the first and only licensed vaccine developed to prevent Lyme borreliosis was LYMERix, with efficacy of nearly $80 \%$ after all three doses had been administered (Nigrovic and Thompson 2007). It stayed on the market for only 4 years, and in 2002 it was withdrawn from the US market due to several reported cases of diversely serious side effects. The most common adverse events noted after receiving at least one dose included pain or reaction at the injection site, joint pain, muscle pain, and headache. It was hypothesized that the vaccine antigen, outer surface protein A (OspA), behaves as an autoantigen and therefore was arthritogenic. The adverse side effects were however never fully confirmed (Shaffer 2019).

VLA15 is the only vaccination program against Lyme borreliosis currently under clinical development. To follow in the footsteps of LYMERix, VLA15 vaccine candidate developed by Valneva is also OspA-based compound. However, it seeks to improve on efficacy and global applicability of the vaccine. LYMERix was a monovalent recombinant vaccine based on bacterial OspA serotype 1 derived from B. burgdorferi sensu stricto. This monovalent OspA serotype 1 vaccine had barely any potential to protect against the disease outside of North America based on the fact that OspA is antigenically very heterogeneous and at least six OspA serotypes are connected with $B$. burgdorferi sensu lato species present in Europe (Wilske et al. 1993). OspA serotype and Borrelia species exhibit a clear connection; B. burgdorferi sensu stricto represents OspA serotype $1 ; B$. afzelii OspA serotype 2; B. garinii OspA serotypes 3, 5, and 6; and B. bavariensis OspA serotype 4. Since OspA protective 
function is to great degree type-specific, a candidate vaccine designed to confer protection against the majority of Lyme borreliosis species has to contain at least two or three antigenic variants of OspA. VLA15 targets the six most common types of Borrelia (Comstedt et al. 2017).

An alternative approach is called pre-exposure prophylaxis, which is based on OspA-specific human monoclonal antibodies that are borreliacidal against a broad range of Borrelia genospecies. Unlike a vaccine, pre-exposure prophylaxis delivers a single defensive antibody and can prevent the transmission of the spirochetes from ticks to mice (Wang et al. 2016). Unless the vaccine is available, the passive administration of a protective human antibody could be an effective approach for borreliosis prophylaxis. The feasibility of using human monoclonal antibodies for pre-exposure prophylaxis has been already shown to be effective against respiratory virus infection (Wang et al. 2011).

OspA, expressed during the tick stage of the pathogen life cycle, is proposed to be an adhesin that binds the spirochetes to the midgut cells using the tick receptor molecule, TROSPA (Pal et al. 2004). The primary mode of action of OspA-based vaccines is to block the migration of the spirochetes from the midgut to the salivary glands of the tick. It is a rather unusual mechanism as it occurs within the tick vector rather than in the vaccinated entity. Several other surface-exposed molecules were identified during this time, and their potential suitability as vaccine candidates have been examined. These, most often lipoproteins, play important roles in various aspects of tick colonization (Fikrig et al. 2004), mammalian infection, and host immune evasion and persistent infection (Lawrenz et al. 2004). This is either through direct binding to the target tissues or by interacting with host factors to create favorable conditions for Borrelia survival. Decorin-binding protein A (DbpA) is an outer surface molecule that is expressed on mammalian host-adapted $B$. burgdorferi. This lipoprotein has exhibited vaccine efficacy against experimental infection in the mammalian model (Hanson et al. 1998; Cassatt et al. 1998) and was shown to be immunogenic during human Lyme borreliosis (Cinco et al. 2000). Fibronectin-binding protein BBK32 plays an important role in the attachment to the extracellular matrix. BBK32 is highly immunogenic and is present in sera of Lyme disease-infected patients (Heikkilä et al. 2002; Lahdenne et al. 2006). BBK32 antisera can interfere with borrelial transmission at various stages of the vector-host life cycle (Fikrig et al. 2000). Outer surface protein C (OspC) is required for early mammalian infection (Grimm et al. 2004) and has been tested as vaccine candidate against B. burgdorferi infection with varying results (Zhong et al. 1999; Earnhart and Marconi 2007).

Vaccination trials testing various lipoprotein candidates have yielded mixed results despite the generation of robust antibody titers. In order to improve on the efficacy, vaccine cocktails containing multiple immunogens have been formulated and tested. A DbpA/OspA combination vaccine protected against 100-fold-higher challenge doses than did either single antigen vaccine or and conferred protection against various Borrelia genospecies (Hanson et al. 2000). Similarly, an OspA/OspC combination showed increased vaccine efficacy compared to single component immunizations (Wallich et al. 2001). A triple combination vaccine of $\mathrm{DbpA}, \mathrm{BBK} 32$, and OspC was shown to be more effective than a single or double antigen vaccine in mice. Interestingly, the ratio of each component has an impact on the overall vaccine efficacy (Brown et al. 2005). The situation is further complicated by the existence of at least five species of B. burgdorferi sensu lato as causes of human Lyme borreliosis: B. burgdorferi sensu stricto, B. afzelii, $B$. bavariensis, B. mayonii and $B$. garinii. To deal with the high degree of heterogeneity of many proteins between the Borrelia strains and species, some research groups have focused on the development of a combination vaccine containing multivalent chimeric vaccinogens with protective effects against diverse Lyme species. As a result, multivalent OspC-based (Earnhart et al. 2007; Earnhart and Marconi 2007) and OspA-based (Wressnigg et al. 2013) chimeric vaccines targeting a broad spectrum of Borrelia species have been developed for prevention of Lyme borreliosis in Europe and the USA, and possibly worldwide. Notably, certain surface proteins that fail to evoke detectable antibody response in the mammalian host during the experimental infection are still able to elicit high-titer and longterm antibody response when applied in a recombinant form (Kung et al. 2016).

Not only the borrelial (lipo)proteins but also glycolipids (Schröder et al. 2003) and polymers consisting of sugars and peptides (Jutras et al. 2019) have shown to be antigenic and could be potential vaccine candidates, or at least serve as adjuvants. The glycolipid, acylated cholesteryl galactoside (ACGal), acts as a strong immunogen as specific antibodies against this compound are frequently found during late stage of the disease (Stübs et al. 2009). Notably, all major Lyme species possess this antigen (Stübs et al. 2009). The strategy to exploit this or somewhat similar molecules is considerably appealing for the development of a single universal "pan-vaccine" to control multiple infectious agents concomitantly (Cabezas-Cruz and de la Fuente 2017). For example, galactose-alpha-1,3-galactose ( $\alpha$-Gal) epitope is highly immunogenic in humans and is present on the surface of a number of deadly pathogens causing diseases such as malaria, sleeping sickness, or Chagas disease. The practical benefits of immunization with $\alpha$-Gal against pathogens with $\alpha$-Gal on their surface have been already demonstrated (CabezasCruz and de la Fuente 2017; de la Fuente et al. 2019).

\section{Anti-tick strategies}

Ticks are obligate hematophagous arthropods and are considered to be second only to mosquitoes as vectors of human 
infectious diseases worldwide. Predominantly due to climate change, ticks have spread to altitudes and latitudes where they were not present earlier (Jore et al. 2011; Jore et al. 2014), and the pathogens transmitted by ticks represent a new health threat in these areas. At least 15 tick-borne bacterial pathogens including Rickettsia, Ehrlichia, Francisella, and several species of the Borrelia burgdorferi sensu lato complex are known to be transmitted by ticks. Viral pathogens that can cause fatal diseases in human such as tick-borne encephalitis virus (TBEV) and Powassan virus are found in ticks as are protozoan parasites of the genus Babesia (Parola and Raoult 2001; Shi et al. 2018). Finding an efficient way to prevent ticks from feeding and therefore transmitting multiple human pathogens would kill more than two birds with one stone and would facilitate the management of many emerging infectious diseases.

\section{Potential vaccine candidates}

The supreme solution to inhibit transmission of multiple pathogens from the tick vector to humans would be development of single universal vaccine. An alternate approach to targeting antigens that are common to many tick-borne pathogens (as discussed above) is to use tick antigens as targets of immune intervention. Recently, the identification and development of such an anti-tick vaccine has been the subject of intensive research (Sprong et al. 2014; Rego et al. 2019). Multiple factors influence the efficacy of an anti-tick vaccine. As any other vaccine candidate, the vaccinogen should firstly be highly immunogenic, be able to provide long-lasting immunity, be associated with a vital function of the tick, and preferably be able to produce cross-protective immune responses against different tick species. Additionally, the immunogen should be expressed during different stages of the tick's life cycle, allowing different tick stages to be targeted. Ideally, future anti-tick vaccine should be applicable to wildlife and domestic animals and eventually also for humans.

There are three families of ticks. The family Ixodidae, or "hard ticks" and the Argasidae, or "soft ticks" are known to transmit pathogens causing diseases to humans. The family Nuttalliellidae, represented by a single species confined to Southern Africa, is not known as a pathogen-associated vector (Keirans et al. 1976). Ticks from Ixodes genus normally take 3 to 7 days to feed, allowing the host to mount an immune response against exposed tick antigens. The pathogens exploit saliva-induced modulation of immune defense exerted by the host to promote their transmission and infection, so-called saliva-assisted transmission (SAT) (Nuttall and Labuda 2004). Tick saliva, introduced into host skin during the feeding process, contains a wide range of proteins with anti-inflammatory, anti-complement, and anti-hemostatic activity (Chmelar et al. 2011; Perner et al. 2018).

The composition of tick saliva changes during the course of tick feeding as the tick counters the dynamic response of the host and appears to differ for different pathogens and tick vector species and possibly can even depend on the mammalian host species (Nuttall 2019). At least a few tick salivary gland proteins seem to facilitate $B$. burgdorferi transmission. Tick histamine release factor (tHRF) is upregulated in B. burgdorferi-infected Ixodes scapularis ticks. Silencing tHRF by RNA interference significantly impairs tick feeding and reduces spirochete burden in mice. Active immunization with recombinant tHRF or passive injection of tHRF antiserum decreases the efficiency of tick feeding and $B$. burgdorferi burden in mice (Dai et al. 2010). Additionally, a 15-kDa tick salivary gland protein Salp15 protects the spirochete directly from host immune responses by binding to the OspC of B. burgdorferi spirochetes (Ramamoorthi et al. 2005). Salp15 is also known to be able to suppress host immunity by binding to $\mathrm{CD} 4$ coreceptor to inhibit $\mathrm{CD} 4^{+}$T-cell activation, inhibiting subsequent receptor ligand-induced cell signaling, and altering the expression levels of cytokines (Anguita et al. 2002; Hovius et al. 2008). Tick salivary lectin pathway inhibitor (TSLPI) is a feeding-induced salivary protein present in I. scapularis (Schuijt et al. 2011) and I. ricinus (Wagemakers et al. 2016). Unlike Salp15, TSPLI does not adhere to B. burgdorferi but instead interacts with the lectin complement cascade. TSLPIsilenced ticks or ticks feeding on mice immunized with TSLPI are impaired in B. burgdorferi transmission. Moreover, B. burgdorferi acquisition and persistence in tick midguts are reduced in ticks feeding on TSLPI-immunized mice, signifying a crucial role in both $B$. burgdorferi transmission to the mammalian host as well as $B$. burgdorferi acquisition and persistence in ticks (Schuijt et al. 2011).

The design of transcriptomic and proteomic studies for conserved tick proteins involved in pathogen transmission is quite cumbersome due to the variation in transmission times for different pathogens during the tick feeding process. These complications could be avoided by targeting the niche organ where the spirochete resides before being transmitted - the tick midgut. The tick midgut protein $\mathrm{Bm} 86$ from Rhipicephalus microplus has been used as an immunogen in two licensed tick vaccines TickGARD (now discontinued) and Gavac since the 1990s (de la Fuente et al. 2007). Bm86based vaccines have diverse efficacies reported worldwide (45-100\%), with the greatest effect on the reduction of larval infestations in subsequent generations (Tabor 2018). Nevertheless, it has limited efficacy against other tick species (de la Fuente et al. 2007). Recently, it has been shown that I. scapularis secretes a protein, PIXR, that modulates the tick gut microbiome and interfere with the ability of $B$. burgdorferi to colonize the tick midgut (Narasimhan et al. 2017). This approach exploits the principle of rendering competent vectors incompetent and targets tick antigens that the parasites encounter during their life cycle. The tick microbiome could possibly be an additional target for the preventive strategies against the tick-borne pathogens (Rego et al. 2019). 


\section{Non-vaccine anti-tick strategies}

Information campaigns are the most common policy measures to reduce the risk of tick-borne diseases. Common recommendations and prevention measures against Lyme borreliosis include avoiding tick-endemic areas, staying on trails while in high-risk areas, the usage of protective clothing, using tick repellents, and checking the body for ticks and removing them before or as soon as possible after they attach (Connally et al. 2009; Slunge and Boman 2018). Risk of Lyme borreliosis from an ecological perspective is measured in terms of density of infected nymphal ticks (Diuk-Wasser et al. 2012). Common methods for killing ticks include the application of acaricides to tick-rich areas, rodents hosts, or to the host animals (Hinckley et al. 2016). The acaricidal treatment of livestock remains the most effective way to prevent ticks from biting and feeding; however, the adverse effects for environmental and public health are more than self-evident (Walker 2014; De Meneghi et al. 2016).

Small mammals are considered the primary hosts of tick larvae and therefore form a key determinant for the abundance of questing nymphs (Perez et al. 2016). Hence, a possible but more difficult strategy to achieve could include landscape modifications and vegetation management strategies in urban and suburban areas in a way that it favors the small mammal species that can build resistance to ticks, a phenomenon in which ticks are unable to feed successfully after several tick infestations (Perez et al. 2016). As an example, repeated infestation of bank voles by larval ticks reduced the feeding success, whereas feeding on wood mice did not negatively affect the successive feeding of ticks (Humair et al. 1999). Changes and growth of agricultural landscapes also significantly affect the communities of small mammals. Wooded habitats are considered favorable for ticks because of temperature and humidity they constantly provide (Perez et al. 2016). Deforestation would definitely be negatively related to tick density because woodland areas act as habitats for ticks and their hosts but the detrimental effects of this action are obvious. Consequently, highly unconventional strategies such as building artificial wood ant nests would be elegant and ecofriendly solutions to reduce the tick density (Zingg et al. 2018), in comparison to rather drastic solutions such as eradication of some mammalian hosts of ticks (Rand et al. 2004).

\section{Reservoir-based approaches}

\section{Oral vaccinations}

The sources of the microbes that cause infectious diseases and where the pathogens can multiply or merely survive until they are transmitted are known as reservoirs. Vector ticks must acquire B. burgdorferi from wildlife reservoirs as there is no clear evidence of a transovarial transmission route (Rollend et al. 2013). Disrupting B. burgdorferi transmission between the tick vector and reservoir hosts is regarded as a promising strategy to reduce human exposure to Lyme borreliosis (Melo et al. 2016). Rodents are a major reservoir for Lyme borreliosis and as such a very promising target to prevent them from getting infected with $B$. burgdorferi. The development of a specific, easily distributable, thermostable, and economically viable oral vaccine for wildlife reservoirs surrounding human communities could significantly reduce the incidence of Lyme borreliosis (Gomes-Solecki et al. 2006).

Oral vaccination is of high interest as a tool to prevent the spread of Lyme borreliosis as it can be used to deliver the vaccine to humans, domestic animals, and wildlife reservoirs of B. burgdorferi. The immunogen can be administered as a purified antigen (Luke et al. 1997) or as a genetically altered Escherichia coli (Fikrig et al. 1991). A number of oral vaccines based in E. coli expressing recombinant OspC, OspB, BBK32 from B. burgdorferi, and Salp25 and Salp15 from Ixodes scapularis were developed. Of the five immunogenic candidates, only OspC induced significant antibody response in mice when they were immunized by intragastric inoculation. Nevertheless, the antibodies did not prevent dissemination of B. burgdorferi as determined by the presence of spirochetes in the ear, heart, and bladder (Melo et al. 2016). Again, OspA seems to be a more promising oral vaccine candidate as oral vaccination of wild white-footed mice resulted in reductions of $23 \%$ and $76 \%$ in the nymphal infection prevalence (Richer et al. 2014). Significant decreases in tick infection were observed within 2-3 years after oral vaccine deployment. The usage of reservoir-based vaccines as part of a strategy to fight the expansion of Lyme borreliosis is also vastly dependent on the development of effective strategies for delivery of the immunogen. One of the promising approaches is the usage of Lactobacillus plantarum as a live vaccine delivery vehicle. These bacteria are naturally associated with the gastrointestinal tract and generally regarded as safe by the FDA. Oral administration of live L. plantarum expressing OspA was shown to be effective in blocking transmission of B. burgdorferi (del Rio et al. 2008). Not only is the deployment of borrelial immunogens in oral vaccines achievable but also the tick antigens can be used to inhibit the transmission of B. burgdorferi. Using the recombinant vaccinia virus, a single dose of the subolesin vaccine resulted in strong immune system response and partial protection from $B$. burgdorferi infection among vaccinated mice (Bensaci et al. 2012).

\section{Immunization by genome editing}

A novel theoretical model for prevention of tick-borne diseases, using CRISPR-based genome editing technology, has been recently suggested (Buchthal et al. 2019). Mice Against Ticks is a proof of principle project that aims to heritably immunize local wild white-footed mouse populations against 
Lyme borreliosis and, potentially, against ticks using antibodies derived from natural adaptive immunity, with the ultimate goal to reduce the reservoir competence of a host for many decades. It is important to emphasize that the protective antibodies have not yet been identified, nor has heritable genome editing been ever achieved in white-footed mice.

\section{Conclusion}

Presently, the use of acaricides constitutes a major component of integrated tick control strategies and therefore indirectly acts as the first line of human-induced defense against a multitude of tick-borne pathogens. However, this is accompanied by the selection of acaricide-resistant ticks and severe pollution of the environment (Kunz and Kemp 1994). Lyme borreliosis is the most common disease spread by ticks in the Northern Hemisphere with an ever increasing incidence, and as such this disease is a major topic on the public health agenda. In order to effectively control the spread of Lyme borreliosis, a multifront battle should be seriously considered, involving environment management, wildlife and domestic animal vaccinations, and of course policymaking. New approaches and strategies that target against Lyme borreliosis, including elements of the tick vector, the reservoir hosts, and the Borrelia pathogen itself, are being developed. Human vaccination is the most effective means of prevention. However, there are a lot of hurdles to overcome, not just regulatory and scientific ones, but public acceptance as well. Let us hope that the challenges present today will be met and an efficient defense against Lyme borreliosis will not only be found but also publicly available in the very near future.

Author contribution MS took the lead role in manuscript preparation with direction and assistance from LG and ROMR.

Funding information This study was supported by the Czech Science Foundation grant 17-21244S and European Union FP7 project ANTIDotE (602272-2).

\section{Compliance with ethical standards}

Conflict of interest The authors declare that they have no conflict of interest.

Ethical approval This article does not contain any studies with human participants or animals performed by any of the authors.

\section{References}

Andre F, Booy R, Bock H, Clemens J, Datta S, John T, Lee B, Lolekha S, Peltola H, Ruff T, Santosham M, Schmitt H (2008) Vaccination greatly reduces disease, disability, death and inequity worldwide.
Bull World Health Organ 86:140-146. https://doi.org/10.2471/ BLT.07.040089

Anguita J, Ramamoorthi N, Hovius JWR, Das S, Thomas V, Persinski R, Conze D, Askenase PW, Rincón M, Kantor FS, Fikrig E (2002) Salp15, an Ixodes scapularis salivary protein, inhibits CD4(+) T cell activation. Immunity 16:849-859

Auwaerter PG, Melia MT (2012) Bullying Borrelia: when the culture of science is under attack. Trans Am Clin Climatol Assoc 123:79-90

Baker PJ, Wormser GP (2017) The clinical relevance of studies on Borrelia burgdorferi persisters. Am J Med 130:1009-1010. https:// doi.org/10.1016/j.amjmed.2017.04.014

Bensaci M, Bhattacharya D, Clark R, Hu LT (2012) Oral vaccination with vaccinia virus expressing the tick antigen subolesin inhibits tick feeding and transmission of Borrelia burgdorferi. Vaccine 30: 6040-6046. https://doi.org/10.1016/j.vaccine.2012.07.053

Brown EL, Kim JH, Reisenbichler ES, Höök M (2005) Multicomponent Lyme vaccine: three is not a crowd. Vaccine 23:3687-3696. https:// doi.org/10.1016/j.vaccine.2005.02.006

Buchthal J, Evans SW, Lunshof J, Telford SR, Esvelt KM (2019) Mice against ticks: an experimental community-guided effort to prevent tick-borne disease by altering the shared environment. Philos Trans R Soc Lond Ser B Biol Sci 374:20180105. https://doi.org/10.1098/ rstb.2018.0105

Cabezas-Cruz A, de la Fuente J (2017) Immunity to $\alpha$-gal: toward a single-antigen pan-vaccine to control major infectious diseases. ACS Cent Sci 3:1140-1142. https://doi.org/10.1021/acscentsci. $7 \mathrm{~b} 00517$

Cadavid D, O'Neill T, Schaefer H, Pachner AR (2000) Localization of Borrelia burgdorferi in the nervous system and other organs in a nonhuman primate model of Lyme disease. Lab Investig J Tech Methods Pathol 80:1043-1054. https://doi.org/10.1038/labinvest. 3780109

Cassatt DR, Patel NK, Ulbrandt ND, Hanson MS (1998) DbpA, but not OspA, is expressed by Borrelia burgdorferi during spirochetemia and is a target for protective antibodies. Infect Immun 66:53795387

Chmelar J, Oliveira CJ, Rezacova P, Francischetti IMB, Kovarova Z, Pejler G, Kopacek P, Ribeiro JMC, Mares M, Kopecky J, Kotsyfakis M (2011) A tick salivary protein targets cathepsin $G$ and chymase and inhibits host inflammation and platelet aggregation. Blood 117:736-744. https://doi.org/10.1182/blood-2010-06293241

Cinco M, Ruscio M, Rapagna F (2000) Evidence of Dbps (decorin binding proteins) among European strains of Borrelia burgdorferi sensu lato and in the immune response of LB patient sera. FEMS Microbiol Lett 183:111-114. https://doi.org/10.1111/j.1574-6968. 2000.tb08942.x

Comstedt P, Schüler W, Meinke A, Lundberg U (2017) The novel Lyme borreliosis vaccine VLA15 shows broad protection against Borrelia species expressing six different OspA serotypes. PLoS One 12: e0184357. https://doi.org/10.1371/journal.pone.0184357

Connally NP, Durante AJ, Yousey-Hindes KM, Meek JI, Nelson RS, Heimer R (2009) Peridomestic Lyme disease prevention: results of a population-based case-control study. Am J Prev Med 37:201-206. https://doi.org/10.1016/j.amepre.2009.04.026

Dai J, Narasimhan S, Zhang L, Liu L, Wang P, Fikrig E (2010) Tick histamine release factor is critical for Ixodes scapularis engorgement and transmission of the Lyme disease agent. PLoS Pathog 6: e1001205. https://doi.org/10.1371/journal.ppat.1001205

de la Fuente J, Almazán C, Canales M, Pérez de la Lastra JM, Kocan KM, Willadsen P (2007) A ten-year review of commercial vaccine performance for control of tick infestations on cattle. Anim Health Res Rev 8:23-28. https://doi.org/10.1017/S1466252307001193

de la Fuente J, Pacheco I, Villar M, Cabezas-Cruz A (2019) The alpha-gal syndrome: new insights into the tick-host conflict and cooperation. Parasit Vectors 12:154. https://doi.org/10.1186/s13071-019-3413-z 
De Meneghi D, Stachurski F, Adakal H (2016) Experiences in tick control by acaricide in the traditional cattle sector in Zambia and Burkina Faso: possible environmental and public health implications. Front Public Health 4:239. https://doi.org/10.3389/fpubh.2016.00239

del Rio B, Dattwyler RJ, Aroso M, Neves V, Meirelles L, Seegers JFML, Gomes-Solecki M (2008) Oral immunization with recombinant Lactobacillus plantarum induces a protective immune response in mice with Lyme disease. Clin Vaccine Immunol CVI 15:14291435. https://doi.org/10.1128/CVI.00169-08

Diuk-Wasser MA, Hoen AG, Cislo P, Brinkerhoff R, Hamer SA, Rowland M, Cortinas R, Vourc'h G, Melton F, Hickling GJ, Tsao JI, Bunikis J, Barbour AG, Kitron U, Piesman J, Fish D (2012) Human risk of infection with Borrelia burgdorferi, the Lyme disease agent, in eastern United States. Am J Trop Med Hyg 86:320-327. https://doi.org/10.4269/ajtmh.2012.11-0395

Earnhart CG, Buckles EL, Marconi RT (2007) Development of an OspCbased tetravalent, recombinant, chimeric vaccinogen that elicits bactericidal antibody against diverse Lyme disease spirochete strains. Vaccine 25:466-480. https://doi.org/10.1016/j.vaccine.2006.07.052

Earnhart CG, Marconi RT (2007) An octavalent Lyme disease vaccine induces antibodies that recognize all incorporated OspC typespecific sequences. Hum Vaccin 3:281-289. https://doi.org/10. 4161/hv.4661

Ebady R, Niddam AF, Boczula AE, Kim YR, Gupta N, Tang TT, Odisho T, Zhi H, Simmons CA, Skare JT, Moriarty TJ (2016) Biomechanics of Borrelia burgdorferi vascular interactions. Cell Rep 16:25932604. https://doi.org/10.1016/j.celrep.2016.08.013

Feng J, Wang T, Shi W, Zhang S, Sullivan D, Auwaerter PG, Zhang Y (2014) Identification of novel activity against Borrelia burgdorferi persisters using an FDA approved drug library. Emerg Microbes Infect 3:e49. https://doi.org/10.1038/emi.2014.53

Feng J, Weitner M, Shi W, Zhang S, Sullivan D, Zhang Y (2015) Identification of additional anti-persister activity against Borrelia burgdorferi from an FDA drug library. Antibiotics 4:397-410. https://doi.org/10.3390/antibiotics4030397

Fikrig E, Barthold SW, Kantor FS, Flavell RA (1991) Protection of mice from Lyme borreliosis by oral vaccination with Escherichia coli expressing OspA. J Infect Dis 164:1224-1227. https://doi.org/10. 1093/infdis/164.6.1224

Fikrig E, Feng W, Barthold SW, Telford SR, Flavell RA (2000) Arthropod- and host-specific Borrelia burgdorferi bbk32 expression and the inhibition of spirochete transmission. J Immunol Baltim Md 1950 164:5344-5351. https://doi.org/10.4049/jimmunol.164.10. 5344

Fikrig E, Pal U, Chen M, Anderson JF, Flavell RA (2004) OspB antibody prevents Borrelia burgdorferi colonization of Ixodes scapularis. Infect Immun 72:1755-1759. https://doi.org/10.1128/iai.72.3. $1755-1759.2004$

Gilmore RD, Kappel KJ, Dolan MC, Burkot TR, Johnson BJ (1996) Outer surface protein $\mathrm{C}(\mathrm{OspC})$, but not $\mathrm{P} 39$, is a protective immunogen against a tick-transmitted Borrelia burgdorferi challenge: evidence for a conformational protective epitope in OspC. Infect Immun 64:2234-2239

Gomes-Solecki MJC, Brisson DR, Dattwyler RJ (2006) Oral vaccine that breaks the transmission cycle of the Lyme disease spirochete can be delivered via bait. Vaccine 24:4440-4449. https://doi.org/10.1016/j. vaccine.2005.08.089

Grimm D, Tilly K, Byram R, Stewart PE, Krum JG, Bueschel DM, Schwan TG, Policastro PF, Elias AF, Rosa PA (2004) Outersurface protein $\mathrm{C}$ of the Lyme disease spirochete: a protein induced in ticks for infection of mammals. Proc Natl Acad Sci U S A 101: 3142-3147. https://doi.org/10.1073/pnas.0306845101

Hanson MS, Cassatt DR, Guo BP, Patel NK, McCarthy MP, Dorward DW, Höök M (1998) Active and passive immunity against Borrelia burgdorferi decorin binding protein a (DbpA) protects against infection. Infect Immun 66:2143-2153
Hanson MS, Patel NK, Cassatt DR, Ulbrandt ND (2000) Evidence for vaccine synergy between Borrelia burgdorferi decorin binding protein a and outer surface protein a in the mouse model of Lyme borreliosis. Infect Immun 68:6457-6460

Heikkilä T, Seppälä I, Saxén H, Panelius J, Peltomaa M, Julin T, Carlsson S-A, Lahdenne P (2002) Recombinant BBK32 protein in serodiagnosis of early and late Lyme borreliosis. J Clin Microbiol 40:1174-1180. https://doi.org/10.1128/JCM.40.4.1174-1180.2002

Hinckley AF, Meek JI, Ray JAE, Niesobecki SA, Connally NP, Feldman KA, Jones EH, Backenson PB, White JL, Lukacik G, Kay AB, Miranda WP, Mead PS (2016) Effectiveness of residential acaricides to prevent Lyme and other tick-borne diseases in humans. J Infect Dis 214:182-188. https://doi.org/10.1093/infdis/jiv775

Hovius JWR, de Jong MAWP, den Dunnen J, Litjens M, Fikrig E, van der Poll T, Gringhuis SI, Geijtenbeek TBH (2008) Salp15 binding to DC-SIGN inhibits cytokine expression by impairing both nucleosome remodeling and mRNA stabilization. PLoS Pathog 4:e31. https://doi.org/10.1371/journal.ppat.0040031

Hubálek Z (2009) Epidemiology of Lyme borreliosis. Curr Probl Dermatol 37:31-50. https://doi.org/10.1159/000213069

Humair PF, Rais O, Gern L (1999) Transmission of Borrelia afzelii from Apodemus mice and Clethrionomys voles to Ixodes ricinus ticks: differential transmission pattern and overwintering maintenance. Parasitology 118(Pt 1):33-42. https://doi.org/10.1017/ s0031182098003564

Jore S, Vanwambeke SO, Viljugrein $\mathrm{H}$, Isaksen $\mathrm{K}$, Kristoffersen AB, Woldehiwet Z, Johansen B, Brun E, Brun-Hansen H, Westermann S, Larsen I-L, Ytrehus B, Hofshagen M (2014) Climate and environmental change drives Ixodes ricinus geographical expansion at the northern range margin. Parasit Vectors 7:11. https://doi.org/10. 1186/1756-3305-7-11

Jore S, Viljugrein H, Hofshagen M, Brun-Hansen $H$, Kristoffersen AB, Nygård K, Brun E, Ottesen P, Sævik BK, Ytrehus B (2011) Multisource analysis reveals latitudinal and altitudinal shifts in range of Ixodes ricinus at its northern distribution limit. Parasit Vectors 4:84. https://doi.org/10.1186/1756-3305-4-84

Jutras BL, Lochhead RB, Kloos ZA, Biboy J, Strle K, Booth CJ, Govers SK, Gray J, Schumann P, Vollmer W, Bockenstedt LK, Steere AC, Jacobs-Wagner C (2019) Borrelia burgdorferi peptidoglycan is a persistent antigen in patients with Lyme arthritis. Proc Natl Acad Sci U S A 116:13498-13507. https://doi.org/10.1073/pnas. 1904170116

Kalmár Z, Mihalca AD, Dumitrache MO, Gherman CM, Magdaș C, Mircean V, Oltean M, Domșa C, Matei IA, Mărcuțan DI, Sándor AD, D’Amico G, Paștiu A, Györke A, Gavrea R, Marosi B, Ionică A, Burkhardt E, Toriay H, Cozma V (2013) Geographical distribution and prevalence of Borrelia burgdorferi genospecies in questing Ixodes ricinus from Romania: a countrywide study. Ticks TickBorne Dis 4:403-408. https://doi.org/10.1016/j.ttbdis.2013.04.007

Keirans JE, Clifford CM, Hoogstraal H, Easton ER (1976) Discovery of Nuttalliella namaqua Bedford (Acarina: Ixodoidea: Nuttalliellidae) in Tanzania and redescription of the female based on scanning electron microcopy. Ann Entomol Soc Am 69:926-932. https://doi.org/ 10.1093/aesa/69.5.926

Krupka I, Straubinger RK (2010) Lyme borreliosis in dogs and cats: background, diagnosis, treatment and prevention of infections with Borrelia burgdorferi sensu stricto. Vet Clin North Am Small Anim Pract 40:1103-1119. https://doi.org/10.1016/j.cvsm.2010.07.011

Kuehn BM (2013) CDC estimates 300,000 US cases of Lyme disease annually. JAMA 310:1110. https://doi.org/10.1001/jama.2013. 278331

Kung F, Kaur S, Smith AA, Yang X, Wilder CN, Sharma K, Buyuktanir O, Pal U (2016) A Borrelia burgdorferi surface-exposed transmembrane protein lacking detectable immune responses supports pathogen persistence and constitutes a vaccine target. J Infect Dis 213: 1786-1795. https://doi.org/10.1093/infdis/jiw013 
Kunz SE, Kemp DH (1994) Insecticides and acaricides: resistance and environmental impact. Rev Sci Tech Int Off Epizoot 13:1249-1286. https://doi.org/10.20506/rst.13.4.816

Lahdenne P, Sarvas H, Kajanus R, Eholuoto M, Sillanpää H, Seppälä I (2006) Antigenicity of borrelial protein BBK32 fragments in early Lyme borreliosis. J Med Microbiol 55:1499-1504. https://doi.org/ 10.1099/jmm.0.46621-0

Lascher S, Goldmann DR (2016) Efficacy of antibiotic prophylaxis for the prevention of Lyme disease after tick bite. Am J Med 129:935937. https://doi.org/10.1016/j.amjmed.2016.05.011

Lawrenz MB, Wooten RM, Norris SJ (2004) Effects of vlsE complementation on the infectivity of Borrelia burgdorferi lacking the linear plasmid lp28-1. Infect Immun 72:6577-6585. https://doi.org/10. 1128/IAI.72.11.6577-6585.2004

Lee J, Wormser GP (2008) Pharmacodynamics of doxycycline for chemoprophylaxis of Lyme disease: preliminary findings and possible implications for other antimicrobials. Int J Antimicrob Agents 31: 235-239. https://doi.org/10.1016/j.ijantimicag.2007.11.011

Ljøstad U, Skogvoll E, Eikeland R, Midgard R, Skarpaas T, Berg A, Mygland A (2008) Oral doxycycline versus intravenous ceftriaxone for European Lyme neuroborreliosis: a multicentre, non-inferiority, double-blind, randomised trial. Lancet Neurol 7:690-695. https:// doi.org/10.1016/S1474-4422(08)70119-4

Luke CJ, Huebner RC, Kasmiersky V, Barbour AG (1997) Oral delivery of purified lipoprotein OspA protects mice from systemic infection with Borrelia burgdorferi. Vaccine 15:739-746. https://doi.org/10. 1016/s0264-410x(97)00219-3

Margos G, Fingerle V, Reynolds S (2019) Borrelia bavariensis: vector switch, niche invasion, and geographical spread of a tick-borne bacterial parasite. Front Ecol Evol 7:401. https://doi.org/10.3389/fevo. 2019.00401

Melo R, Richer L, Johnson DL, Gomes-Solecki M (2016) Oral immunization with OspC does not prevent tick-borne Borrelia burgdorferi infection. PLoS One 11:e0151850. https://doi.org/10.1371/journal. pone. 0151850

Middelveen MJ, Sapi E, Burke J, Filush KR, Franco A, Fesler MC, Stricker RB (2018) Persistent Borrelia infection in patients with ongoing symptoms of Lyme disease. Healthcare 6:2. https://doi. org/10.3390/healthcare6020033

Montgomery RR, Schreck K, Wang X, Malawista SE (2006) Human neutrophil calprotectin reduces the susceptibility of Borrelia burgdorferi to penicillin. Infect Immun 74:2468-2472. https://doi. org/10.1128/IAI.74.4.2468-2472.2006

Moriarty TJ, Norman MU, Colarusso P, Bankhead T, Kubes P, Chaconas G (2008) Real-time high resolution 3D imaging of the Lyme disease spirochete adhering to and escaping from the vasculature of a living host. PLoS Pathog 4:e1000090. https://doi.org/10.1371/journal. ppat. 1000090

Nadelman RB, Nowakowski J, Fish D, Falco RC, Freeman K, McKenna D, Welch P, Marcus R, Agüero-Rosenfeld ME, Dennis DT, Wormser GP, Tick Bite Study Group (2001) Prophylaxis with single-dose doxycycline for the prevention of Lyme disease after an Ixodes scapularis tick bite. N Engl J Med 345:79-84. https:// doi.org/10.1056/NEJM200107123450201

Narasimhan S, Schuijt TJ, Abraham NM, Rajeevan N, Coumou J, Graham M, Robson A, Wu M-J, Daffre S, Hovius JW, Fikrig E (2017) Modulation of the tick gut milieu by a secreted tick protein favors Borrelia burgdorferi colonization. Nat Commun 8:184. https://doi.org/10.1038/s41467-017-00208-0

Nigrovic LE, Thompson KM (2007) The Lyme vaccine: a cautionary tale. Epidemiol Infect 135:1-8. https://doi.org/10.1017/ S0950268806007096

Norman MU, Moriarty TJ, Dresser AR, Millen B, Kubes P, Chaconas G (2008) Molecular mechanisms involved in vascular interactions of the Lyme disease pathogen in a living host. PLoS Pathog 4: e1000169. https://doi.org/10.1371/journal.ppat.1000169
Nuttall PA (2019) Tick saliva and its role in pathogen transmission. Wien Klin Wochenschr:1-12. https://doi.org/10.1007/s00508-019-1500-y

Nuttall PA, Labuda M (2004) Tick-host interactions: saliva-activated transmission. Parasitology 129(Suppl):S177-S189. https://doi.org/ $10.1017 / \mathrm{s} 0031182004005633$

Pal U, Li X, Wang T, Montgomery RR, Ramamoorthi N, Desilva AM, Bao F, Yang X, Pypaert M, Pradhan D, Kantor FS, Telford S, Anderson JF, Fikrig E (2004) TROSPA, an Ixodes scapularis receptor for Borrelia burgdorferi. Cell 119:457-468. https://doi.org/10. 1016/j.cell.2004.10.027

Parola P, Raoult D (2001) Ticks and tickborne bacterial diseases in humans: an emerging infectious threat. Clin Infect Dis Off Publ Infect Dis Soc Am 32:897-928. https://doi.org/10.1086/319347

Perez G, Bastian S, Agoulon A, Bouju A, Durand A, Faille F, Lebert I, Rantier Y, Plantard O, Butet A (2016) Effect of landscape features on the relationship between Ixodes ricinus ticks and their small mammal hosts. Parasit Vectors 9:20. https://doi.org/10.1186/ s13071-016-1296-9

Perner J, Kropáčková S, Kopáček P, Ribeiro JMC (2018) Sialome diversity of ticks revealed by RNAseq of single tick salivary glands. PLoS Negl Trop Dis 12:e0006410. https://doi.org/10.1371/journal. pntd.0006410

Piesman J, Hojgaard A, Ullmann AJ, Dolan MC (2014) Efficacy of an experimental azithromycin cream for prophylaxis of tick-transmitted Lyme disease spirochete infection in a murine model. Antimicrob Agents Chemother 58:348-351. https://doi.org/10.1128/AAC. 01932-13

Pothineni VR, Wagh D, Babar MM, Inayathullah M, Solow-Cordero D, Kim K-M, Samineni AV, Parekh MB, Tayebi L, Rajadas J (2016) Identification of new drug candidates against Borrelia burgdorferi using high-throughput screening. Drug Des Devel Ther 10:13071322. https://doi.org/10.2147/DDDT.S101486

Probert WS, Johnson BJ (1998) Identification of a $47 \mathrm{kDa}$ fibronectinbinding protein expressed by Borrelia burgdorferi isolate B31. Mol Microbiol 30:1003-1015

Ramamoorthi N, Narasimhan S, Pal U, Bao F, Yang XF, Fish D, Anguita J, Norgard MV, Kantor FS, Anderson JF, Koski RA, Fikrig E (2005) The Lyme disease agent exploits a tick protein to infect the mammalian host. Nature 436:573-577. https://doi.org/10.1038/ nature 03812

Rand PW, Lubelczyk C, Holman MS, Lacombe EH, Smith RP (2004) Abundance of Ixodes scapularis (Acari: Ixodidae) after the complete removal of deer from an isolated offshore island, endemic for Lyme disease. J Med Entomol 41:779-784. https://doi.org/10.1603/00222585-41.4.779

Rego ROM, Trentelman JJA, Anguita J, Nijhof AM, Sprong H, Klempa B, Hajdusek O, Tomás-Cortázar J, Azagi T, Strnad M, Knorr S, Sima R, Jalovecka M, Fumačová Havlíková S, Ličková M, Sláviková M, Kopacek P, Grubhoffer L, Hovius JW (2019) Counterattacking the tick bite: towards a rational design of antitick vaccines targeting pathogen transmission. Parasit Vectors 12: 229. https://doi.org/10.1186/s13071-019-3468-x

Ribeiro JM, Mather TN, Piesman J, Spielman A (1987) Dissemination and salivary delivery of Lyme disease spirochetes in vector ticks (Acari: Ixodidae). J Med Entomol 24:201-205. https://doi.org/10. 1093/jmedent/24.2.201

Richer LM, Brisson D, Melo R, Ostfeld RS, Zeidner N, Gomes-Solecki M (2014) Reservoir targeted vaccine against Borrelia burgdorferi: a new strategy to prevent Lyme disease transmission. J Infect Dis 209: 1972-1980. https://doi.org/10.1093/infdis/jiu005

Rollend L, Fish D, Childs JE (2013) Transovarial transmission of Borrelia spirochetes by Ixodes scapularis: a summary of the literature and recent observations. Ticks Tick-Borne Dis 4:46-51. https:// doi.org/10.1016/j.ttbdis.2012.06.008

Rudenko N, Golovchenko M, Kybicova K, Vancova M (2019) Metamorphoses of Lyme disease spirochetes: phenomenon of 
Borrelia persisters. Parasit Vectors 12:237. https://doi.org/10.1186/ s13071-019-3495-7

Rudenko N, Golovchenko M, Vancova M, Clark K, Grubhoffer L, Oliver JH (2016) Isolation of live Borrelia burgdorferi sensu lato spirochaetes from patients with undefined disorders and symptoms not typical for Lyme borreliosis. Clin Microbiol infect 22:267-e9-15. https://doi.org/10.1016/j.cmi.2015.11.009

Schröder NWJ, Schombel U, Heine H, Göbel UB, Zähringer U, Schumann RR (2003) Acylated cholesteryl galactoside as a novel immunogenic motif in Borrelia burgdorferi sensu stricto. J Biol Chem 278:33645-33653. https://doi.org/10.1074/jbc.M305799200

Schuijt TJ, Coumou J, Narasimhan S, Dai J, Deponte K, Wouters D, Brouwer M, Oei A, Roelofs JJTH, van Dam AP, van der Poll T, Van't Veer C, Hovius JW, Fikrig E (2011) A tick mannose-binding lectin inhibitor interferes with the vertebrate complement cascade to enhance transmission of the Lyme disease agent. Cell Host Microbe 10:136-146. https://doi.org/10.1016/j.chom.2011.06.010

Schwameis M, Kündig T, Huber G, von Bidder L, Meinel L, Weisser R, Aberer E, Härter G, Weinke T, Jelinek T, Fätkenheuer G, Wollina U, Burchard G-D, Aschoff R, Nischik R, Sattler G, Popp G, Lotte W, Wiechert D, Eder G, Maus O, Staubach-Renz P, Gräfe A, Geigenberger V, Naudts I, Sebastian M, Reider N, Weber R, Heckmann M, Reisinger EC, Klein G, Wantzen J, Jilma B (2017) Topical azithromycin for the prevention of Lyme borreliosis: a randomised, placebo-controlled, phase 3 efficacy trial. Lancet Infect Dis 17:322-329. https://doi.org/10.1016/S1473-3099(16)30529-1

Shaffer L (2019) Inner workings: Lyme disease vaccines face familiar challenges, both societal and scientific. Proc Natl Acad Sci U S A 116:19214-19217. https://doi.org/10.1073/pnas.1913923116

Shapiro ED, Wormser GP (2017) Prophylaxis with topical azithromycin against Lyme borreliosis. Lancet Infect Dis 17:246-248. https://doi. org/10.1016/S1473-3099(16)30551-5

Sharma B, Brown AV, Matluck NE, Hu LT, Lewis K (2015) Borrelia burgdorferi, the causative agent of Lyme disease, forms drugtolerant persister cells. Antimicrob Agents Chemother 59:46164624. https://doi.org/10.1128/AAC.00864-15

Shi J, Hu Z, Deng F, Shen S (2018) Tick-borne viruses. Virol Sin 33:2143. https://doi.org/10.1007/s12250-018-0019-0

Slunge D, Boman A (2018) Learning to live with ticks? The role of exposure and risk perceptions in protective behaviour against tickborne diseases. PLoS One 13:6. https://doi.org/10.1371/journal. pone. 0198286

Smith R, Takkinen J (2006) Lyme borreliosis: Europe-wide coordinated surveillance and action needed? Euro Surveill Bull Eur Sur Mal Transm Eur Commun Dis Bull 11:E060622.1

Sprong H, Trentelman J, Seemann I, Grubhoffer L, Rego RO, Hajdušek O, Kopáček P, Šíma R, Nijhof AM, Anguita J, Winter P, Rotter B, Havlíková S, Klempa B, Schetters TP, Hovius JW (2014) ANTIDotE: anti-tick vaccines to prevent tick-borne diseases in Europe. Parasit Vectors 7:77. https://doi.org/10.1186/1756-3305-777

Stanek G, Strle F (2018) Lyme borreliosis-from tick bite to diagnosis and treatment. FEMS Microbiol Rev 42:233-258. https://doi.org/10. 1093/femsre/fux047

Stanek G, Wormser GP, Gray J, Strle F (2012) Lyme borreliosis. Lancet Lond Engl 379:461-473. https://doi.org/10.1016/S0140-6736(11) 60103-7

Steere AC (2001) Lyme disease. N Engl J Med 345:115-125. https://doi. org/10.1056/NEJM200107123450207

Steere AC, Malawista SE, Snydman DR, Shope RE, Andiman WA, Ross MR, Steele FM (1977) Lyme arthritis: an epidemic of oligoarticular arthritis in children and adults in three Connecticut communities. Arthritis Rheum 20:7-17. https://doi.org/10.1002/art.1780200102

Stricker RB, Middelveen MJ (2018) Better drugs for Lyme disease: focus on the spirochete. Infect Drug Resist 11:1437-1439. https://doi.org/ 10.2147/IDR.S176831
Strnad M, Elsterová J, Schrenková J, Vancová M, Rego ROM, Grubhoffer L, Nebesářová J (2015) Correlative cryo-fluorescence and cryo-scanning electron microscopy as a straightforward tool to study host-pathogen interactions. Sci Rep 5:18029. https://doi.org/ 10.1038/srep18029

Strnad M, Hönig V, Růžek D, Grubhoffer L, Rego ROM (2017) Europewide meta-analysis of Borrelia burgdorferi sensu lato prevalence in questing Ixodes ricinus ticks. Appl Environ Microbiol 83:15. https:// doi.org/10.1128/AEM.00609-17

Stübs G, Fingerle V, Wilske B, Göbel UB, Zähringer U, Schumann RR, Schröder NWJ (2009) Acylated cholesteryl galactosides are specific antigens of borrelia causing Lyme disease and frequently induce antibodies in late stages of disease. J Biol Chem 284:1332613334. https://doi.org/10.1074/jbc.M809575200

Tabor AE (2018) The enigma of identifying new cattle tick vaccine antigens. Ticks Tick-Borne Pathog. https://doi.org/10.5772/intechopen. 81145

Tanner T, Marks R (2008) Delivering drugs by the transdermal route: review and comment. Skin Res Technol Off J Int Soc Bioeng Skin ISBS Int Soc Digit Imaging Skin ISDIS Int Soc Skin Imaging ISSI 14:249-260. https://doi.org/10.1111/j.1600-0846.2008.00316.x

Tappe J, Jordan D, Janecek E, Fingerle V, Strube C (2014) Revisited: Borrelia burgdorferi sensu lato infections in hard ticks (Ixodes ricinus) in the city of Hanover (Germany). Parasit Vectors 7:441. https://doi.org/10.1186/1756-3305-7-441

Timmaraju VA, Theophilus PAS, Balasubramanian K, Shakih S, Luecke DF, Sapi E (2015) Biofilm formation by Borrelia burgdorferi sensu lato. FEMS Microbiol Lett 362:fnv120. https://doi.org/10.1093/ femsle/fnv120

van Duijvendijk G, Coipan C, Wagemakers A, Fonville M, Ersöz J, Oei A, Földvári G, Hovius J, Takken W, Sprong H (2016) Larvae of Ixodes ricinus transmit Borrelia afzelii and B. miyamotoi to vertebrate hosts. Parasit Vectors 9:97. https://doi.org/10.1186/s13071016-1389-5

Vancová M, Rudenko N, Vaněček J, Golovchenko M, Strnad M, Rego ROM, Tichá L, Grubhoffer L, Nebesářová J (2017) Pleomorphism and viability of the Lyme disease pathogen Borrelia burgdorferi exposed to physiological stress conditions: a correlative cryofluorescence and cryo-scanning electron microscopy study. Front Microbiol 8:596. https://doi.org/10.3389/fmicb.2017.00596

Vechtova P, Sterbova J, Sterba J, Vancova M, Rego ROM, Selinger M, Strnad M, Golovchenko M, Rudenko N, Grubhoffer L (2018) A bite so sweet: the glycobiology interface of tick-host-pathogen interactions. Parasit Vectors 11:594. https://doi.org/10.1186/s13071-0183062-7

Wagemakers A, Coumou J, Schuijt TJ, Oei A, Nijhof AM, van 't Veer C, van der Poll T, Bins AD, Hovius JWR (2016) An Ixodes ricinus tick salivary lectin pathway inhibitor protects Borrelia burgdorferi sensu lato from human complement. Vector Borne Zoonotic Dis Larchmt N 16:223-228. https://doi.org/10.1089/vbz.2015.1901

Walker AR (2014) Ticks and associated diseases: a retrospective review. Med Vet Entomol 28(Suppl 1):1-5. https://doi.org/10.1111/mve. 12031

Wallich R, Siebers A, Jahraus O, Brenner C, Stehle T, Simon MM (2001) DNA vaccines expressing a fusion product of outer surface proteins a and $\mathrm{C}$ from Borrelia burgdorferi induce protective antibodies suitable for prophylaxis but not for resolution of Lyme disease. Infect Immun 69:2130-2136. https://doi.org/10.1128/IAI.69.4.2130-2136. 2001

Wang D, Bayliss S, Meads C (2011) Palivizumab for immunoprophylaxis of respiratory syncytial virus (RSV) bronchiolitis in high-risk infants and young children: a systematic review and additional economic modelling of subgroup analyses. Health Technol assess winch Engl 15:iii-iv-i1-124. https://doi.org/10.3310/hta15050

Wang Y, Kern A, Boatright NK, Schiller ZA, Sadowski A, Ejemel M, Souders CA, Reimann KA, Hu L, Thomas WD, Klempner MS 
(2016) Pre-exposure prophylaxis with OspA-specific human monoclonal antibodies protects mice against tick transmission of Lyme disease spirochetes. J Infect Dis 214:205-211. https://doi.org/10. 1093/infdis/jiw151

Warshafsky S, Lee DH, Francois LK, Nowakowski J, Nadelman RB, Wormser GP (2010) Efficacy of antibiotic prophylaxis for the prevention of Lyme disease: an updated systematic review and metaanalysis. J Antimicrob Chemother 65:1137-1144. https://doi.org/10. 1093/jac/dkq097

Wilske B, Preac-Mursic V, Göbel UB, Graf B, Jauris S, Soutschek E, Schwab E, Zumstein G (1993) An OspA serotyping system for Borrelia burgdorferi based on reactivity with monoclonal antibodies and OspA sequence analysis. J Clin Microbiol 31:340-350

Wormser GP, Shapiro ED, Strle F (2017) Studies that report unexpected positive blood cultures for Lyme Borrelia- are they valid? Diagn Microbiol Infect Dis 89:178-181. https://doi.org/10.1016/j. diagmicrobio.2017.07.009

Wressnigg N, Pöllabauer E-M, Aichinger G, Portsmouth D, Löw-Baselli A, Fritsch S, Livey I, Crowe BA, Schwendinger M, Brühl P, Pilz A, Dvorak T, Singer J, Firth C, Luft B, Schmitt B, Zeitlinger M, Müller
M, Kollaritsch H, Paulke-Korinek M, Esen M, Kremsner PG, Ehrlich HJ, Barrett PN (2013) Safety and immunogenicity of a novel multivalent OspA vaccine against Lyme borreliosis in healthy adults: a double-blind, randomised, dose-escalation phase 1/2 trial. Lancet Infect Dis 13:680-689. https://doi.org/10.1016/S14733099(13)70110-5

Zhong W, Gern L, Stehle T, Museteanu C, Kramer M, Wallich R, Simon MM (1999) Resolution of experimental and tick-borne Borrelia burgdorferi infection in mice by passive, but not active immunization using recombinant OspC. Eur J Immunol 29:946-957. https:// doi.org/10.1002/(SICI)1521-4141(199903)29:03<946::AIDIMMU946>3.0.CO;2-P

Zingg S, Dolle P, Voordouw MJ, Kern M (2018) The negative effect of wood ant presence on tick abundance. Parasit Vectors 11:164. https://doi.org/10.1186/s13071-018-2712-0

Publisher's note Springer Nature remains neutral with regard to jurisdictional claims in published maps and institutional affiliations. 